\title{
Posterior reversible encephalopathy syndrome and spinal extradural hematoma in an elderly patient
}

\author{
Kouhei Onishi ${ }^{1}$, Susumu Uchida ${ }^{1}$, Hirotaka Fudaba ${ }^{1}$, Yukari Kawasaki ${ }^{1}$, Masaki \\ Morishige $^{1}$, and Minoru Fujiki ${ }^{1}$ \\ ${ }^{1}$ Oita University
}

February 22, 2021

\begin{abstract}
Posterior reversible encephalopathy syndrome (PRES) is identified on magnetic resonance imaging by posterior predominant white and gray matter lesions. PRES secondary to spinal disease is very rare. We report a case of clinical and imaging findings about PRES associated with spinal epidural hematoma.

Posterior reversible encephalopathy syndrome and spinal epidural hematoma

in an elderly patient

Kouhei Onishi, Susumu Uchida, Hirotaka Fudaba, Yukari Kawasaki, Masaki Morishige, Minoru Fujiki

Department of Neurosurgery, Graduate School of Medicine, Oita University, Oita, Japan
\end{abstract}

Corresponding Author: Kouhei Onishi

Department of Neurosurgery, School of Medicine, Oita University

1-1, Idaigaoka, Hasama-machi, Yufu, Oita 879-5593, Japan

TEL: +81-97-586-5861, FAX: +81-97-586-5869, E-mail: k-onishi@oita-u.ac.jp

Key Clinical Massage

Various factors, such as persistent hypertension and renal failure caused onset of posterior reversible encephalopathy syndrome triggered by spinal epidural hematoma. We must pay attention to risk factors of PRES even in spinal disease.

Keywords

Posterior reversible encephalopathy syndrome, spine, epidural hematoma

Introduction

Posterior reversible encephalopathy syndrome (PRES) is identified on magnetic resonance (MR) imaging by posterior predominant white and gray matter lesions. The common clinical features are headache, seizures, and visual loss, often in the setting of renal failure, accelerated hypertension and following administration of immunosuppressive drugs. It is widely accepted that the mechanism of PRES is the generation of vasogenic edema caused by failure of cerebral autoregulation and the production of cytotoxic edema due to ischemia. PRES secondary to spinal disease is very rare. Only a few reports show PRES occurred in patients with 
spinal epidural hematoma. Here, we report a case of clinical and imaging findings about PRES associated with spinal epidural hematoma.

\section{Case history}

A 81-year-old woman suddenly presented with intense neck pain and developed rapidly progressive quadriparesis. She had previously been diagnosed with hypertension and chronic renal failure. Neurological examination showed severe right-sided dominant tetraplegia. Sensory deficit was difficult to exam because of her confusion.

\section{Investigation and Treatment}

On admission to the emergency hospital, her blood pressure was $152 / 82 \mathrm{mmHg}$ and pulse was $60 / \mathrm{min}$. She had mild delirium. Routine blood analysis showed renal function tests were raised (blood urea nitrogen $28.0 \mathrm{mg} / \mathrm{dl}$ and serum creatinine $2.11 \mathrm{mg} / \mathrm{dl}$ ). Serum electrolytes ware normal.

Brain MR imaging showed left occipital white matter and left cerebellum slight hyperintensities on fluidattenuated inversion recovery (FLAIR)-sequences (Fig.1 a). MR imaging of the spine showed a large epidural hematoma compressing the dorsolateral surface of spinal cord at the levels C2-Th4 (Fig.1 c-d) and intramedullary hematoma at C4/5 (Fig.1 e). No abnormally enlarged vessels were observed on T2 weighted image.

Next day, on admission to our hospital, she was still confused, and her clinical findings were not improved. Brain and spinal MR performed, spinal epidural hematoma was not decreased and white matter of right temporooccipital lobes and cerebellum FLAIR high lesions were revealed clearly (Fig.1 b). She underwent a C3-T1 hemi-laminectomy and removal of epidural hematoma.

\section{Outcome and Follow-up}

On the postoperative stage, she complained of delirium, partial seizure, persistent hypertension, and worsen renal failure. Use of antihypertensive \& anticonvulsant medication and undergoing temporary hemodialysis (Fig.4).

Post operative MR spine demonstrate that epidural hematoma was removed but spinal edema still remained (Fig.3 c-e). Brain MR done 17days after surgery showed complete reversibility of the hyper-intense lesions on FLAIR (Fig.3 b).

Her general status was improved gradually and no more seizures were observed. Her arms and legs weakness remained and she kept on aggressive physiotherapy. Her neurological findings were improved gradually and she changed hospital to undergo rehabilitation. 4 months later, she could walk without assistance.

\section{Discussion}

PRES was first described in 1996 and is a well-known syndrome that typically presents with a headache, seizures and visual disturbance [1]. The most common cause of PRES is sever hypertension, renal failure, immunosuppressant therapy, chemo therapy, eclampsia and autoimmune disorder. In connection with spinal disease, though several reports show PRES associated with autonomic dysreflexia in spinal cord injury patients [2-4], only a few reports with spinal epidural hematoma. PRES due to spinal epidural hematoma has occurred such rarity with 2 cases reported previously [5,6] (Table1). Among them, only 2 cases caused

by spontaneous spinal epidural hematoma including our case. Case No.2 is postoperative case. Spontaneous spinal epidural hematoma itself could not lead to PRES, so several risk factors are connected.

\section{Conclusion}

We report a case of PRES due to acute spinal epidural hematoma. In our case, various factors including persistent hypertension, renal failure caused onset of PRES triggered by spinal epidural hematoma. We must pay attention to risk factors of PRES even in spinal disease.

\section{Acknowledgments}


No relevant acknowledgments.

Conflict of Interest Statement

The authors declare that there was no conflict of interest regarding the publication of this paper.

Author contribution

Kouhei Onishi: drafted the manuscript and contributed to treatment of the patient.

Susumu Uchida: drafted the manuscript and contributed to treatment of the patient.

Hirotaka Fudaba: contributed to treatment of the patient and participated in critical review and in the revision of the manuscript.

Yukari Kawasaki: participated in critical review and in the revision of the manuscript.

Masaki Morishige: participated in critical review and in the revision of the manuscript.

Minoru Fujiki: participated in critical review and in the revision of the manuscript.

All authors have read and approved the final manuscript.

\section{References}

1. Hinchey J, Chaves C, Appignani B. 1996. A reversible posterior leukoencephalopathy syndrome. N Engll J Med. 334:494-500

2. CJ Chaves. 2008. Reversible posterior leukoencepalopathy in a patient with autonomic dysreflexia: a case report. Spinal Cord 46: 760-761.

3. Yamashita T. 2012. Cerebral Hemorrhage Due to Posterior Reversible Encephalopathy Syndrome Associated With Autonomic Dysreflexia in a Spinal Cord Injury Patient. Neurol Med Chir 52: 640-643.

4. Farooq S. 2017. Acute visual loss in a patient with spinal cord injury. Spinal Cord Ser Cases 3: 17080

5. P Striano. 2007. Posterior reversible encephalopathy syndrome and spinal epidural hematoma in a hypertensive patient. European Journal of Anaeshesiology 24: 1057-1069.

6. Chittur VG. 2011. Posterior Rversible Encephalopathy Syndrome in a Case of Postoperative Spinal Extradural Hematoma: Case Report and Review of Literature. Asian Spine Jurnal 5: 64-67.
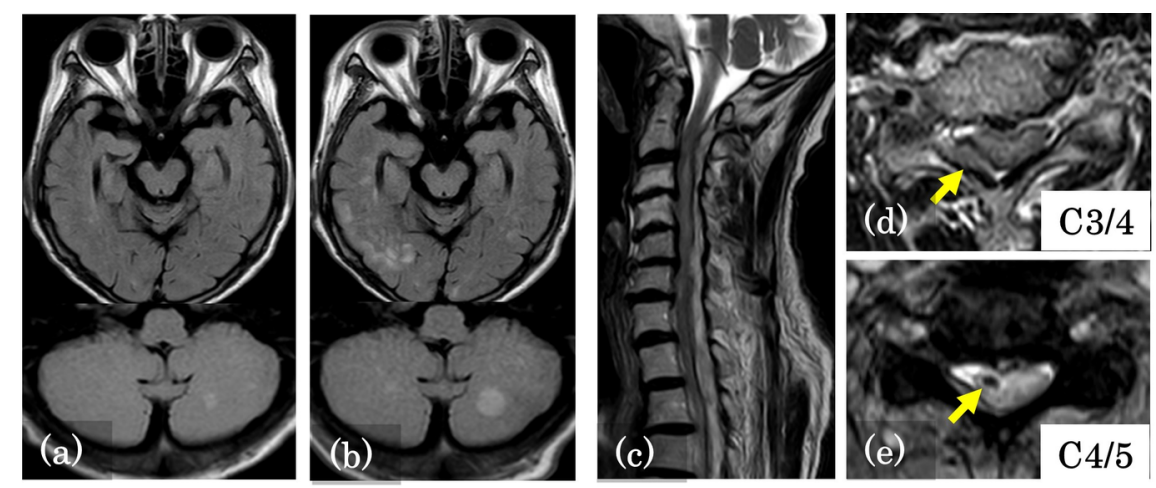

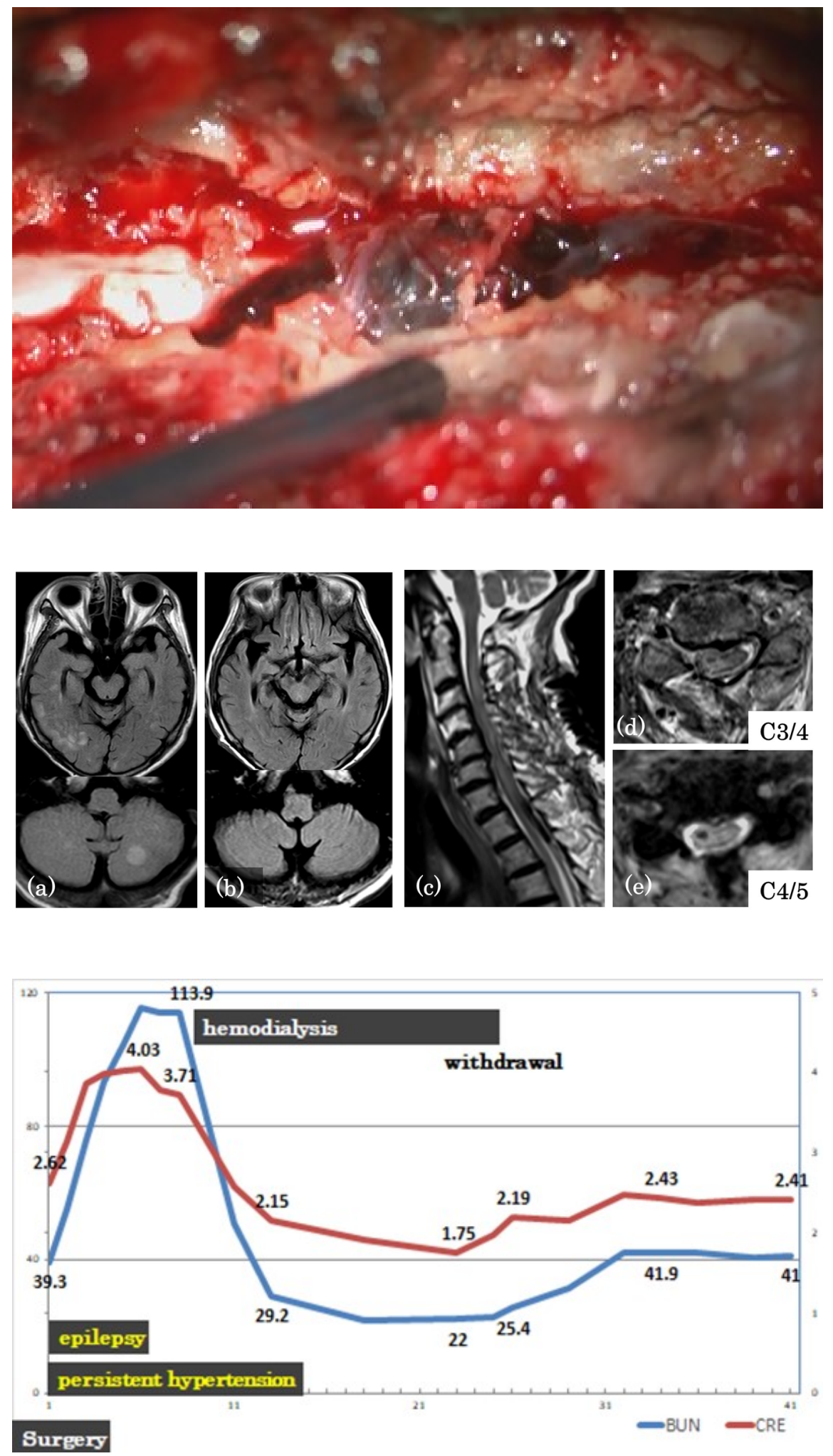
Table 1

Reviews of PRES secondary to spinal epidural hematoma

\begin{tabular}{|c|c|c|c|c|c|c|}
\hline No. & Author & $\begin{array}{l}\operatorname{Age}(y) / \\
\text { Sex }\end{array}$ & $\begin{array}{l}\text { Acute neurological } \\
\text { symptom }\end{array}$ & Risk factor & Lesion on MRI & $\begin{array}{l}\text { Clinical } \\
\text { outcome }\end{array}$ \\
\hline 1 & $\begin{array}{l}\text { P striano } \\
(2007)\end{array}$ & $49 / \mathrm{F}$ & $\begin{array}{c}\text { Seizure } \\
\text { Headache } \\
\text { Visual disturbance }\end{array}$ & Hypertension & $\begin{array}{c}\text { Bilateral parieto- } \\
\text { occipital lobes }\end{array}$ & Full recover \\
\hline 2 & $\begin{array}{l}\text { Chittur VG } \\
(2011)\end{array}$ & $14 / \mathrm{F}$ & $\begin{array}{c}\text { Seizure } \\
\text { Headache } \\
\text { Visual disturbance }\end{array}$ & $\begin{array}{l}\text { No risk factors } \\
\text { (spinal cord } \\
\text { compression) }\end{array}$ & $\begin{array}{c}\text { Bilateral frontal } \\
\text { and } \\
\text { parietooccipital } \\
\text { lobes }\end{array}$ & $\begin{array}{l}\text { Lower limb } \\
\text { weakness }\end{array}$ \\
\hline 3 & Present case & $81 / \mathrm{F}$ & $\begin{array}{l}\text { Seizure } \\
\text { Confusion }\end{array}$ & $\begin{array}{l}\text { Hypertension } \\
\text { Renal failure }\end{array}$ & $\begin{array}{c}\text { Bilateral } \\
\text { temporooccipital } \\
\text { lobes and } \\
\text { cerebellum }\end{array}$ & $\begin{array}{c}\text { Mild } \\
\text { quadriparesis }\end{array}$ \\
\hline
\end{tabular}

